\title{
Estrutura e processos da Vigilância em Saúde em municípios mineiros: uma análise qualiquantitativa
}

\author{
Structure and processes in Health Surveillance in \\ municipalities of Minas Gerais: a quali-quantitative analysis
}

\author{
Jean Ezequiel Limongi ${ }^{1}$, Bruna Fernanda Antonio Caldeira ${ }^{1}$, \\ Ludimila Andrade Gonçalves ${ }^{1}$, Carla Guimarães Félix', \\ Rosuíta Fratari Bonito², Vivianne Peixoto da Silva ${ }^{1}$
}

\begin{abstract}
Resumo
Introdução: A descentralização das ações de saúde pública, operacionalizada a partir da criação do Sistema Único de Saúde, alterou sobremaneira os sistemas de saúde municipais no Brasil. O objetivo deste estudo foi avaliar de forma qualiquantitativa os sistemas de Vigilância em Saúde (VS) de três municípios mineiros de pequeno e médio porte e associar com os serviços de saúde prestados. Métodos: Um instrumento de coleta de dados estruturado e entrevistas semiestruturadas foram utilizados para avaliar a estrutura e os processos realizados na VS dos municípios, respectivamente. Resultados: Vigilância Epidemiológica, Sanitária e Vigilância da Situação de Saúde apresentaram a melhor estrutura. Vigilância ambiental, Vigilância à Saúde do Trabalhador e Promoção da Saúde possuíam estruturas precárias nos três municípios e, na maioria das vezes, compartilhada com outros setores. Os entrevistados atribuíram a boa execução dos processos de vigilância nos municípios muito mais à proatividade dos profissionais e articulação com outros setores do que propriamente pela estrutura física. Conclusão: A VS nos municípios mineiros ainda é incipiente, porém projetos pioneiros como o ProFVS-MG podem alterar sobremaneira a realidade local.
\end{abstract}

Palavras-chave: vigilância em saúde pública; descentralização; avaliação em saúde.

\section{Abstract}

Introduction: The decentralization of public health measures, operationalized through the creation of the Sistema Único de Saúde (Unified Health System), greatly altered municipal health systems in Brazil. The aim of this study was to qualitatively and quantitatively evaluate small and medium-size health monitoring systems (HS) in three municipalities of Minas Gerais and associate this with the health services provided. Methods: A data collection instrument of structured and semi-structured interviews was used to assess the structure and processes established in HS municipalities, respectively. Results: Epidemiological Monitoring, Sanitation Monitoring and Health Situation Monitoring had the best structure. Environmental Health Monitoring, Occupational Health Monitoring and Health Promotion had poor structures in the three municipalities, and was frequently shared with other sectors. Respondents principally attributed good performance of monitoring procedures to the proactivity of professionals and collaboration with other sectors, rather than to the physical structure itself. Conclusions: HS in the municipalities of Minas Gerais is still incipient, but pioneering projects such as the SHSP-MG can greatly change the local reality.

Keywords: public health surveillance; decentralization; health evaluation.

\footnotetext{
${ }^{1}$ Curso de Gestão em Saúde Ambiental, Instituto de Geografia, Universidade Federal de Uberlândia (UFU) - Uberlândia (MG), Brasil.

${ }^{2}$ Faculdade de Medicina, Universidade Federal de Uberlândia (UFU) - Uberlândia (MG), Brasil.

Trabalho realizado na Universidade Federal de Uberlândia (UFU) - Uberlândia (MG), Brasil.

Endereço para correspondência: Jean Ezequiel Limongi - Universidade Federal de Uberlândia (UFU), Avenida João Naves de Ávila, 2121 - Santa Mônica -

CEP: 38408-100 - Uberlândia (MG), Brasil - Email: jeanlimongi@gmail.com

Fonte de financiamento: nenhuma.

Conflito de interesses: nada a declarar.
} 


\section{INTRODUÇÃO}

O Sistema Único de Saúde (SUS) foi criado pela Constituição Federal de 1988 e regulamentado pelas Leis n. ${ }^{\circ} 8080 / 90$ e $\mathrm{n}^{\circ} 8.142 / 90$, tornando-se uma importante política pública que alterou sobremaneira o sistema de saúde brasileiro ${ }^{1}$. Dentre as suas diretrizes organizacionais, a regionalização e a descentralização do sistema e das ações de saúde foram as que mais impactaram os sistemas de saúde municipais, levando ao processo da municipalização, em que a gestão da saúde pública e grande parte do poder decisório foram atribuídas aos municípios ${ }^{2}$. No entanto, os instrumentos normativos que regulamentaram este processo, as Normas Operacionais Básicas do SUS, publicadas nos anos de 1991, 1993 e 1996, foram editadas de forma a não se considerar a heterogeneidade dos municípios nas diferentes regiões inter e intraestaduais, o que levou a limitações na operacionalização da descentralização. Na prática, o que se formou foram distintos sistemas municipais de saúde, com diferentes potenciais de resolução de problemas, mas que, na maioria das vezes, exibem baixa capacidade de autonomia para gerir de forma independente os serviços de saúde².

No Estado de Minas Gerais, dentre os 853 municípios mineiros, apenas 3,8\% (32/853) deles possuem mais de 100.000 habitantes e 78,2\% (667/853) possuem menos de 20.000 habitantes $^{3}$. Estes municípios têm passado por franca transição epidemiológica, demográfica e nutricional e com uma Vigilância em Saúde (VS) distante do território, pouco integrada internamente e com baixo potencial de resultados para o cidadão (Said, 2016, comunicação pessoal). Neste contexto, uma iniciativa inovadora proposta em 2012 pelo governo do Estado de Minas Gerais, e ainda em vigência atualmente, foi o Projeto de Fortalecimento da Vigilância em Saúde (ProFVS-MG). Este projeto tem o intuito de fortalecer os sistemas de saúde municipais, incentivando os municípios mineiros a organizar os sistemas locais de Vigilância em Saúde (VS) e a cumprir indicadores que são previamente definidos pelo governo estadual. O cumprimento das ações estipuladas nas áreas de Vigilância Epidemiológica (VIGEP), Vigilância Sanitária (VISA), Vigilância à Saúde do Trabalhador (VISAT), Vigilância Ambiental (VIGIAM), Vigilância da Situação de Saúde e Promoção da Saúde é vinculado a um incentivo financeiro mensal aos municípios aderidos. Este incentivo é proporcional ao elenco de indicadores a serem cumpridos, os quais são subdivididos em três níveis de complexidade. Os municípios, juntamente com a assessoria técnica da Secretaria Estadual de Saúde, avaliam a sua estrutura de recursos humanos, tecnológica e físico-mobiliária e assim definem qual elenco específico a ser assumido ${ }^{4}$. No ProFVS-MG, atualmente, $100 \%$ dos municípios estão aderidos (Said, 2016, comunicação pessoal).

Estudos aprofundados sobre a estrutura e processos dos sistemas de vigilância em saúde municipais são inexistentes. Neste sentido, este estudo propõe uma avaliação qualiquantitativa dos sistemas de VS de três municípios mineiros de pequeno e médio porte, fazendo associação com os serviços de saúde prestados, utilizando as mesmas variáveis e indicadores propostos no ProFVS-MG.

\section{MÉTODOS}

Foi pesquisada a estrutura e os processos de VS em três municípios localizados no Triângulo Mineiro e Noroeste de Minas. Estes municípios foram identificados como municípios A, B e C. Conforme a classificação do Instituto Brasileiro de Geografia e Estatística (IBGE), os municípios A e B foram classificados como de pequeno porte classe 3 e 4 (6.569 habitantes e 15.290 habitantes, respectivamente) e o município $C$, de médio porte, classe 6 ( 97.171 habitantes) $)^{5}$.

A estrutura da VS nos três municípios foi pesquisada por meio de um instrumento de coleta de dados estruturado padronizado pelo Ministério da Saúde 6 , o mesmo utilizado no ProFVS-MG para avaliar a estrutura de VS nos municípios mineiros. Foi analisada a escolaridade dos gestores e servidores vinculados à VS, as legislações relacionadas à vigilância dos municípios, programas desenvolvidos pelas equipes, insumos básicos, recursos humanos, estrutura física e burocrática, equipamentos e meios de transporte.

Para a análise dos processos executados pela VS nos municípios, foram realizadas entrevistas semiestruturadas com um instrumento de coleta de dados adaptado de Laguardia et al. ${ }^{7}$, com vistas a analisar as ações das seis áreas da VS. Os processos pesquisados foram baseados nos indicadores estipulados no ProFVS-MG. Para cada processo, foram analisados os pontos fortes relacionados à realização das ações e/ou os pontos fracos ou dificuldades encontradas, que culminaram na não realização. Para uniformizar a coleta de dados, as questões foram norteadas pelos seguintes parâmetros: (i) capacitação e suporte em educação permanente; (ii) articulação entre os profissionais da equipe; (iii) articulação com outros setores; (iv) sistemas de informação; (v) relação com a gestão municipal; (vi) recursos humanos; (vii) recursos materiais.

As entrevistas foram realizadas com os profissionais de saúde responsáveis pela coordenação e/ou gestão dos serviços de VS. Todas as entrevistas foram gravadas por meio de um gravador digital. Essas foram transcritas na íntegra, submetidas à análise de conteúdo temático e operacionalizadas em três etapas: (i) pré-análise, que constitui a organização do material a ser analisado mediante leitura e demarcação dos trechos a serem trabalhados; (ii) codificação, classificação e categorização do material; e (iii) interpretação dos resultados'.

Esta pesquisa foi aprovada pelo Comitê de Ética em Pesquisa da Universidade Federal de Uberlândia, conforme as normas da Resolução CNS 466/12 (Parecer No. 1.067.139/2015). 


\section{RESULTADOS}

Nos três municípios, foram entrevistados 14 profissionais, sendo 1 no município de pequeno porte A (responsável por toda a VS no município), 7 no município de pequeno porte $B$ e 6 no município de médio porte.

Apenas no município de pequeno porte B existia coordenação geral de VS.

No município de pequeno porte A, existia cobertura de cem por cento da Estratégia Saúde da Família (ESF): três unidades de Atenção Primária à Saúde (UAPS) e um Núcleo de Apoio à Saúde da Família (NASF). O município de pequeno porte $B$ também era coberto em cem por cento pela ESF, com cinco
UAPS, porém não possuía NASF. No município de médio porte, havia quatorze UAPS e um NASF, com cobertura da ESF de 39\%. Em relação à situação funcional dos servidores, os municípios de pequeno porte $\mathrm{A}, \mathrm{B}$ e de médio porte possuíam no seu quadro a seguinte proporção de concursados/contratados, respectivamente, 3/5, 4/3;28/87.

Entre os três municípios, apenas o município de pequeno porte A não possuía espaço físico para desenvolvimento de atividades da VISA (Tabela 1). Em todos os municípios, a VIGEP possuía sala exclusiva. Possuíam também salas de vacinas, porém a estrutura adequada completa não foi observada em nenhum deles. A estrutura da VIGIAM era

Tabela 1. Análise da estrutura da Vigilância epidemiológica, Vigilância Sanitária e Vigilância Ambiental em três municípios mineiros de pequeno e médio porte, 2015

\begin{tabular}{|c|c|c|c|c|c|c|c|c|c|c|c|c|}
\hline \multirow{3}{*}{ Vigilâncias } & \multicolumn{12}{|c|}{ Presença dos itens pesquisados na estrutura das vigilâncias } \\
\hline & \multicolumn{4}{|c|}{ Município de pequeno porte $A$} & \multicolumn{4}{|c|}{ Município de pequeno porte $B$} & \multicolumn{4}{|c|}{ Município de médio porte } \\
\hline & Sim & Não & Compartilhado & $\mathbf{N}$ & Sim & Não & Compartilhado & $\mathbf{N}$ & Sim & Não & Compartilhado & $\mathbf{N}$ \\
\hline \multicolumn{13}{|l|}{ Vigilância Sanitária } \\
\hline $\begin{array}{l}\text { Possui espaço } \\
\text { físico para o } \\
\text { desenvolvimento } \\
\text { das atividades } \\
\text { de Vigilância } \\
\text { Sanitária? }\end{array}$ & - & Não & - & NA & Sim & - & - & 02 & Sim & - & - & 01 \\
\hline $\begin{array}{l}\text { Possui } \\
\text { almoxarifado } \\
\text { de materiais e } \\
\text { equipamentos } \\
\text { de Vigilância } \\
\text { Sanitária? }\end{array}$ & - & Não & - & NA & Sim & - & - & 01 & - & Não & - & NA \\
\hline Possui freezer? & - & Não & - & NA & - & Não & - & NA & Sim & - & - & 01 \\
\hline $\begin{array}{l}\text { Possui máquina } \\
\text { fotográfica? }\end{array}$ & Sim & - & - & 01 & Sim & - & - & 01 & Sim & - & - & 03 \\
\hline $\begin{array}{l}\text { Computador } \\
\text { exclusivo para } \\
\text { a Vigilância } \\
\text { Sanitária? }\end{array}$ & Sim & - & - & 01 & Sim & - & - & 02 & Sim & - & - & 02 \\
\hline Internet? & Sim & - & - & 01 & - & - & Compartilhada & 01 & Sim & - & - & 02 \\
\hline $\begin{array}{l}\text { Aparelho de } \\
\text { telefone/Aparelho } \\
\text { de fax }\end{array}$ & Sim & - & - & 01 & - & Não & - & NA & Sim & - & - & 01 \\
\hline $\begin{array}{l}\text { Possui meio de } \\
\text { transporte? }\end{array}$ & - & - & Compartilhado & 04 & Sim & - & - & 01 & Sim & - & - & 03 \\
\hline \multicolumn{13}{|c|}{ Vigilância epidemiológica } \\
\hline $\begin{array}{l}\text { Possui sala } \\
\text { administrativa? }\end{array}$ & Sim & - & - & 01 & Sim & - & - & 01 & Sim & - & - & 01 \\
\hline $\begin{array}{l}\text { Possui sala de } \\
\text { vacinas? }\end{array}$ & Sim & - & - & 01 & Sim & - & - & 05 & Sim & - & - & 15 \\
\hline $\begin{array}{l}\text { Possui câmaras } \\
\text { frias em salas de } \\
\text { vacinas? }\end{array}$ & - & Não & - & NA & Sim & - & - & 05 & - & Não & - & NA \\
\hline $\begin{array}{l}\text { Possui geladeiras } \\
\text { exclusivas nas } \\
\text { salas de vacina? }\end{array}$ & Sim & - & - & 02 & Sim & - & - & 05 & Sim & - & - & 15 \\
\hline
\end{tabular}

N: Número absoluto; NA: Não aplicável 
Tabela 1. Continuação...

\begin{tabular}{|c|c|c|c|c|c|c|c|c|c|c|c|c|}
\hline \multirow{3}{*}{ Vigilâncias } & \multicolumn{12}{|c|}{ Presença dos itens pesquisados na estrutura das vigilâncias } \\
\hline & \multicolumn{4}{|c|}{ Município de pequeno porte $\mathrm{A}$} & \multicolumn{4}{|c|}{ Município de pequeno porte $B$} & \multicolumn{4}{|c|}{ Município de médio porte } \\
\hline & Sim & Não & Compartilhado & $\mathbf{N}$ & Sim & Não & Compartilhado & $\mathbf{N}$ & Sim & Não & Compartilhado & $\mathbf{N}$ \\
\hline $\begin{array}{l}\text { Possui } \\
\text { computadores } \\
\text { exclusivos na sala } \\
\text { de vacinas? }\end{array}$ & Sim & - & - & 01 & Sim & - & - & 05 & - & Não & - & NA \\
\hline $\begin{array}{l}\text { Possui } \\
\text { aparelhos de ar } \\
\text { condicionado na } \\
\text { sala de vacina? }\end{array}$ & - & Não & - & NA & Sim & - & - & 05 & Sim & - & - & 04 \\
\hline $\begin{array}{l}\text { Possui geradores } \\
\text { na sala de } \\
\text { estoque de } \\
\text { imunobiológicos? }\end{array}$ & - & Não & - & NA & - & Não & - & NA & - & Não & - & NA \\
\hline $\begin{array}{l}\text { Possui meio de } \\
\text { transporte? }\end{array}$ & - & - & Compartilhado & 04 & - & - & Compartilhado & 01 & Sim & - & - & 04 \\
\hline \multicolumn{13}{|c|}{ Vigilância ambiental } \\
\hline $\begin{array}{l}\text { Possui sala } \\
\text { administrativa? }\end{array}$ & Sim & - & - & 01 & Sim & - & - & 02 & - & - & Compartilhada & 01 \\
\hline $\begin{array}{l}\text { Possui } \\
\text { Laboratório de } \\
\text { Endemias? }\end{array}$ & - & Não & - & NA & - & Não & - & NA & Sim & - & - & 01 \\
\hline $\begin{array}{l}\text { Possui } \\
\text { Laboratório de } \\
\text { Vigilância da } \\
\text { Qualidade da } \\
\text { Água? }\end{array}$ & - & Não & - & NA & - & Não & - & NA & - & Não & - & NA \\
\hline $\begin{array}{l}\text { Possui Centro } \\
\text { de Controle de } \\
\text { Zoonoses? }\end{array}$ & - & Não & - & NA & - & Não & - & NA & Sim & - & - & 01 \\
\hline $\begin{array}{l}\text { Possui } \\
\text { almoxarifado de } \\
\text { inseticidas? }\end{array}$ & Sim & - & - & 01 & Sim & - & - & 01 & - & Não & - & NA \\
\hline $\begin{array}{l}\text { Possui } \\
\text { almoxarifado de } \\
\text { equipamentos } \\
\text { (Bomba costal, } \\
\text { EPI)? }\end{array}$ & Sim & - & - & 01 & - & Não & - & NA & - & Não & - & NA \\
\hline $\begin{array}{l}\text { Possui } \\
\text { equipamentos } \\
\text { específicos? }\end{array}$ & - & Não & - & $\mathrm{Na}$ & Sim & - & - & 09 & Sim & - & - & 07 \\
\hline $\begin{array}{l}\text { Possui meio de } \\
\text { transporte? }\end{array}$ & - & - & Compartilhado & 04 & Sim & - & - & 02 & Sim & - & - & 15 \\
\hline
\end{tabular}

N: Número absoluto; NA: Não aplicável

precária nos três municípios pesquisados, faltando inclusive uma sala administrativa exclusiva no município de médio porte (Tabela 1). Apenas no município de pequeno porte A existia uma sala administrativa exclusiva para a VISAT. Meios de transporte, porém, eram compartilhados nos municípios de pequeno porte $\mathrm{A}$ e médio porte, enquanto que o município de pequeno porte $B$ não possuía qualquer meio de transporte para este setor (Tabela 2). Nos três municípios, o setor de Promoção da Saúde utilizava os espaços públicos (praças e quadras poliesportivas) para o desenvolvimento das ações de atividades físicas (Tabela 2). O município de médio porte contava com uma equipe multidisciplinar formada por fisioterapeutas, nutricionistas e psicólogos no suporte a este setor. Em relação ao setor de Vigilância da Situação em Saúde, em todos os municípios existia a estrutura de espaço físico e de recursos de comunicação (Tabela 2).

$\mathrm{Da}$ análise das entrevistas com os coordenadores das vigilâncias nos municípios, emergiram quatro eixos de discussão: (i) pontos fortes para a execução das ações; (ii) pontos fracos que inviabilizam a execução das ações; (iii) dificuldades internas; 
Tabela 2. Análise da estrutura da Vigilância à Saúde do Trabalhador, Promoção da Saúde e Vigilância da Situação em Saúde em três municípios mineiros de pequeno e médio porte, 2015

Presença dos itens pesquisados na estrutura das vigilâncias

\begin{tabular}{|c|c|c|c|c|c|c|c|c|c|c|c|c|}
\hline \multirow{3}{*}{ Vigilâncias } & \multicolumn{12}{|c|}{ Presença dos itens pesquisados na estrutura das vigilâncias } \\
\hline & \multicolumn{4}{|c|}{ Município de pequeno porte $A$} & \multicolumn{4}{|c|}{ Município de pequeno porte $B$} & \multicolumn{4}{|c|}{ Município de médio porte } \\
\hline & Sim & Não & Compartilhado & $\mathbf{N}$ & Sim & Não & Compartilhado & $\mathbf{N}$ & Sim & Não & Compartilhado & $\mathbf{N}$ \\
\hline \multicolumn{13}{|c|}{ Vigilância à saúde do trabalhador } \\
\hline $\begin{array}{l}\text { Possui sala } \\
\text { administrativa } \\
\text { destinada aos } \\
\text { técnicos da } \\
\text { Vigilância à Saúde } \\
\text { do Trabalhador? }\end{array}$ & Sim & - & - & 01 & - & - & Compartilhada & 01 & - & - & Compartilhada & 01 \\
\hline $\begin{array}{l}\text { Computador } \\
\text { exclusivo para } \\
\text { vigilância à saúde } \\
\text { do trabalhador? }\end{array}$ & Sim & - & - & 01 & - & Sim & - & 01 & Sim & - & - & 01 \\
\hline Internet? & Sim & - & - & 01 & - & - & Compartilhada & 01 & Sim & - & - & 01 \\
\hline $\begin{array}{l}\text { Aparelho de } \\
\text { telefone/Aparelho } \\
\text { de fax }\end{array}$ & Sim & - & - & 01 & - & - & Compartilhado & 01 & Sim & - & - & 01 \\
\hline $\begin{array}{l}\text { Possui meio de } \\
\text { transporte? }\end{array}$ & - & - & Compartilhado & 04 & - & Não & - & NA & - & - & Compartilhado & 01 \\
\hline \multicolumn{13}{|l|}{ Promoção da saúde } \\
\hline $\begin{array}{l}\text { Possui espaços } \\
\text { físicos para o } \\
\text { desenvolvimento } \\
\text { de ações de } \\
\text { atividades } \\
\text { físicas/práticas } \\
\text { corporais? }\end{array}$ & - & - & Compartilhado & 02 & - & - & Compartilhado & 9 & - & - & Compartilhado & 12 \\
\hline $\begin{array}{l}\text { Possui sala de } \\
\text { espera equipada } \\
\text { (áudio/vídeo, } \\
\text { mobília) nos } \\
\text { serviços de saúde? }\end{array}$ & - & Não & - & NA & Sim & - & - & 05 & - & Não & - & NA \\
\hline $\begin{array}{l}\text { Possui } \\
\text { equipamentos } \\
\text { específicos? }\end{array}$ & - & Não & - & NA & - & Não & - & NA & Sim & - & - & 01 \\
\hline $\begin{array}{l}\text { Possui meio de } \\
\text { transporte? }\end{array}$ & - & - & Compartilhado & 04 & - & - & Compartilhado & 01 & - & - & Compartilhado & 01 \\
\hline \multicolumn{13}{|c|}{ Vigilância da situação em saúde } \\
\hline $\begin{array}{l}\text { Possui sala para } \\
\text { os Sistemas de } \\
\text { Informação? }\end{array}$ & Sim & - & - & 01 & - & - & Compartilhada & 01 & Sim & - & - & 01 \\
\hline $\begin{array}{l}\text { Possui sala } \\
\text { administrativa } \\
\text { para os técnicos } \\
\text { do Sistema de } \\
\text { Informação? }\end{array}$ & $\operatorname{Sim}$ & - & - & 01 & - & - & Compartilhada & 01 & - & - & Compartilhada & 01 \\
\hline $\begin{array}{l}\text { Possui } \\
\text { computador } \\
\text { exclusivo para } \\
\text { a digitação dos } \\
\text { Sistemas de } \\
\text { Informação em } \\
\text { Saúde } \\
\end{array}$ & Sim & - & - & 01 & Sim & - & - & 03 & Sim & - & - & 01 \\
\hline Internet? & Sim & - & - & 01 & - & - & Compartilhada & 01 & Sim & - & - & 01 \\
\hline $\begin{array}{l}\text { Aparelho de } \\
\text { telefone/Aparelho } \\
\text { de fax }\end{array}$ & $\operatorname{Sim}$ & - & - & 01 & - & - & Compartilhado & 01 & Sim & - & - & 01 \\
\hline
\end{tabular}

N: Número absoluto; NA: Não aplicável 
e (iv) dificuldades externas, os quais se encontram apresentados, segundo o município pesquisado, nas Tabelas 3 e 4.

Em relação à VISA, os três municípios diferem quanto aos seus principais pontos fortes. Dificuldades internas e externas nas ações de VISA foram relatadas nos três municípios (Tabelas 3 e 4). Dentre as dificuldades apontadas, frise-se a falta de autonomia no município A, conforme fala da entrevistada a seguir:

[...] ela- referência à VISA - realiza hoje - inspeção - dos PSFs e do hospital com supervisão da SRS, ela não está com total autonomia". (Entrevistada; município A).

O aumento da demanda, devido ao crescimento do município e consequente aumento do número de estabelecimentos comerciais e de saúde, foi evidenciado como dificuldade externa no município de médio porte e, por isso, grande parte dos estabelecimentos é fiscalizado apenas quando há denúncias ou surtos de infecção alimentar. Essa dificuldade é descrita na fala de uma entrevistada no fragmento a seguir:

Nós procuramos atender a demanda, mas nem sempre é possível, porque precisamos fazer notificações, vistorias, inspeções e relatórios, além da Regional de Saúde mandar as denúncias que chegam lá pra nós investigarmos, e isso acontece todos os dias. (Entrevistada 1; município de médio porte).

Além disso, a discordância da equipe em relação aos procedimentos adotados na rotina, também foi relatada, conforme pode ser observado na fala da entrevistada abaixo:

Uma atividade educativa é a queima dos alimentos. Aí a gente leva todos eles pro lixão e lá a gente coloca fogo e vai embora só quando termina tudo, porque às vezes pode ter alguém lá que vai apagar pra ficar com a comida. Até teve gente já me procurando pra vê se não podia dar. Aí teve uma vez lá que um senhor pegou sabe, aí assim eu não criei caso não, o outro colega deu farinha, acho que foi farinha mesmo. Tava vencida que a gente tava lá pra queimar e ele queria dar pro cavalo, aí eu não concordei sabe, mas o colega quis dar, tudo bem. (Entrevistada 2; município B).

Na VIGEP, a articulação entre os profissionais da equipe foi o principal ponto forte nos três municípios (Tabelas 3 e 4). A articulação com outros setores, no entanto, aparece como ponto fraco no município A, como relatado pela entrevistada:

[...] aqui é a meta que a gente tem mais dificuldade é o de sintomático respiratório. Porque a gente depende do médico passar o exame, às vezes, fica só ali no consultório e não chega pra gente o exame de $B A A R$ para ser feito, ou a pessoa faz particular com receio de que alguém fique sabendo que há suspeita de tuberculose. Tem esses pontos negativos, e o sintomático respiratório ele tem outro agravo, ele consta que a pessoa tenha que estar tossindo aproximadamente há duas semanas, e aqui ninguém espera esse tempo de duas semanas para procurar o médico, então é uma contradição que a gente acha, essas são as dificuldades que a gente encontra, por isso, não estamos alcançando essa meta. (Entrevistada; município A).

De forma geral, os pontos fracos nos municípios na VIGEP se concentram principalmente em questões relativas à formação/qualificação dos profissionais (Tabelas 3 e 4).
Na VIGIAM, apesar de a capacitação e suporte em educação permanente serem consideradas pontos fortes nos municípios $A$ e $B$, foi relatado neste último município como dificuldade interna o desconhecimento de algumas ações. No município de médio porte, foi relatado o preenchimento incorreto de fichas de notificação, como a de acidentes por animais peçonhentos, por exemplo (Tabelas 3 e 4).

A articulação com outros setores foi um importante ponto forte das equipes relacionadas à VISAT nos municípios A e de médio porte, devido principalmente à interação existente entre os agentes comunitários de saúde, enfermeiros, médicos e digitadores do sistema de informação em saúde. Não foram relatados pontos fracos ou dificuldades nesta vigilância em nenhum município (Tabelas 3 e 4).

Nas atividades de promoção da saúde, a articulação com outros setores e entre os profissionais da equipe foram considerados pontos fortes em todos os municípios. No entanto, a falta de espaço físico e recursos materiais, além de dificuldades externas como a adesão da população aos programas oferecidos, bem como a condição social da população, dificultavam a execução e o êxito das ações, como pode ser visto na fala a seguir sobre a vigilância alimentar e nutricional de crianças de 0 a 5 anos:

Muitas vezes [referente à dificuldade de adesão] é porque falta dinheiro para a família comprar alimento e a criança só faz uma refeição, por isso nós damos as vitaminas que estão faltando ou alimentos que conseguimos arrecadar. (Entrevistada 4; município de médio porte).

As ações de atividade física e práticas corporais destinadas aos idosos são realizadas ao ar livre, em praças ou logradouros públicos, nos três municípios, como constatado na fala da entrevistada:

[...] a gente tem dois projetos voltados para a saúde do idoso. Um no período da manhã que épara idosos que tenham problemas de coluna, mais dificuldade de andar, que são exercícios que podem ser feitos sentados e mais leves, e tem também, o grupo de idosos Vida Ativa e Saudável na Praça, que acontece duas vezes por semana na academia da praça no horário das 18:00. (Entrevistada; município A).

Na Vigilância da Situação em Saúde, os municípios de pequeno porte $\mathrm{A}$ e $\mathrm{B}$, consideravam como principal ponto forte a capacitação e suporte em educação permanente, enquanto o município de médio porte considerava a articulação com outros setores e entre os profissionais da equipe. Apenas este município relatou ponto fraco nesta vigilância, sendo que a carência de recursos materiais foi relatada seis vezes durante a entrevista (Tabelas 3 e 4).

\section{DISCUSSÃO}

O modelo baseado na VS ganhou força nas últimas décadas no Brasil e deixou de ser um setor acessório na prática de saúde pública para se tornar o eixo norteador de todo o processo de gestão. A tônica deste modelo busca respostas efetivas 
Tabela 3. Análise das ações da Vigilância em Saúde em três municípios mineiros de pequeno e médio porte, 2015

$\begin{array}{cccc}\text { Vigilâncias } & \begin{array}{c}\text { Categorias } \\ \text { Temáticas }\end{array} & \begin{array}{c}\text { Município de } \\ \text { pequeno porte A }\end{array} & \begin{array}{c}\text { Município de pequeno } \\ \text { porte B }\end{array}\end{array}$

Articulação entre os profissionais da equipe

Pontos fortes Capacitação e suporte em educação permanente

Recursos humanos
Capacitação e suporte em educação permanente

Articulação com outros setores Articulação entre os profissionais da equipe Recursos humanos

\section{Município de médio porte}

Articulação com outros setores

Articulação entre os profissionais da equipe

Recursos humanos

Recursos materiais Sistemas de informação

\begin{tabular}{|c|c|c|c|c|}
\hline \multirow{4}{*}{ Vigilância Sanitária } & & & & \multirow[b]{2}{*}{ - } \\
\hline & Pontos fracos & - & - & \\
\hline & $\begin{array}{l}\text { Dificuldades } \\
\text { Internas }\end{array}$ & Falta de autonomia & $\begin{array}{l}\text { Discordância entre a equipe } \\
\text { quanto a alimentos vencidos } \\
\text { Articulação com outros setores } \\
\text { para ações educativas } \\
\text { Conflitos de interesse da } \\
\text { gestão e estabelecimentos }\end{array}$ & $\begin{array}{l}\text { Código Sanitário } \\
\text { ultrapassado }\end{array}$ \\
\hline & $\begin{array}{c}\text { Dificuldades } \\
\text { Externas } \\
\end{array}$ & - & - & Aumento da demanda \\
\hline \multirow{4}{*}{$\begin{array}{c}\text { Vigilância } \\
\text { Epidemiológica }\end{array}$} & Pontos fortes & $\begin{array}{l}\text { Capacitação e suporte em } \\
\text { educação permanente } \\
\text { Articulação entre os } \\
\text { profissionais da equipe } \\
\text { Recursos humanos } \\
\text { Sistemas de informação }\end{array}$ & $\begin{array}{c}\text { Articulação entre os } \\
\text { profissionais da equipe } \\
\text { Articulação com outros setores } \\
\text { Recursos materiais } \\
\text { Capacitação e suporte em } \\
\text { educação permanente } \\
\text { Sistemas de informação } \\
\text { Recursos humanos } \\
\end{array}$ & $\begin{array}{l}\text { Articulação com outros } \\
\text { setores } \\
\text { Articulação entre os } \\
\text { profissionais da equipe } \\
\text { Recursos materiais } \\
\text { Sistemas de informação }\end{array}$ \\
\hline & Pontos fracos & $\begin{array}{c}\text { Articulação entre } \\
\text { profissionais da equipe } \\
\text { Recursos humanos }\end{array}$ & - & $\begin{array}{l}\text { Capacitação e suporte em } \\
\text { educação permanente }\end{array}$ \\
\hline & $\begin{array}{l}\text { Dificuldades } \\
\text { Internas }\end{array}$ & Dificuldade de gestão & - & $\begin{array}{l}\text { Poucos profissionais } \\
\text { responsáveis pela } \\
\text { capacitação nos programas }\end{array}$ \\
\hline & $\begin{array}{c}\text { Dificuldades } \\
\text { Externas }\end{array}$ & Adesão da população & - & - \\
\hline \multirow[t]{4}{*}{ Vigilância Ambiental } & Pontos fortes & $\begin{array}{c}\text { Capacitação e suporte em } \\
\text { educação permanente } \\
\text { Articulação com outros } \\
\text { setores } \\
\text { Recursos materiais } \\
\text { Relação com a gestão } \\
\text { municipal } \\
\text { Recursos humanos } \\
\text { Sistemas de informação }\end{array}$ & $\begin{array}{l}\text { Capacitação e suporte em } \\
\text { educação permanente } \\
\text { Articulação entre os } \\
\text { profissionais da equipe } \\
\text { Relação com a gestão } \\
\text { municipal Recursos humanos } \\
\text { Recursos materiais } \\
\text { Sistemas de informação }\end{array}$ & $\begin{array}{l}\text { Articulação com outros } \\
\text { setores } \\
\text { Articulação entre os } \\
\text { profissionais da equipe } \\
\text { Sistemas de informação } \\
\text { Recursos humanos } \\
\text { Recursos materiais }\end{array}$ \\
\hline & Pontos fracos & - & Articulação com outros setores & Recursos humanos \\
\hline & $\begin{array}{l}\text { Dificuldades } \\
\text { Internas }\end{array}$ & - & $\begin{array}{l}\text { Desconhecimento das ações } \\
\text { Absenteísmo de servidores }\end{array}$ & $\begin{array}{c}\text { Preenchimento incorreto } \\
\text { de fichas } \\
\text { Rotatividade de } \\
\text { profissionais }\end{array}$ \\
\hline & $\begin{array}{l}\text { Dificuldades } \\
\text { Externas }\end{array}$ & - & - & $\begin{array}{l}\text { Localização geográfica das } \\
\text { áreas a serem trabalhadas }\end{array}$ \\
\hline
\end{tabular}


Tabela 3. Continuação...

\begin{tabular}{|c|c|c|c|c|}
\hline Vigilâncias & $\begin{array}{l}\text { Categorias } \\
\text { Temáticas }\end{array}$ & $\begin{array}{c}\text { Município de } \\
\text { pequeno porte } A\end{array}$ & $\begin{array}{c}\text { Município de pequeno } \\
\text { porte } B\end{array}$ & Município de médio porte \\
\hline \multirow[t]{4}{*}{$\begin{array}{l}\text { Vigilância à Saúde do } \\
\text { Trabalhador }\end{array}$} & Pontos fortes & $\begin{array}{l}\text { Articulação com outros } \\
\text { setores } \\
\text { Articulação entre os } \\
\text { profissionais da equipe } \\
\text { Capacitação e suporte em } \\
\text { educação permanente }\end{array}$ & $\begin{array}{c}\text { Capacitação e suporte em } \\
\text { educação permanente } \\
\text { Articulação entre os } \\
\text { profissionais da equipe } \\
\text { Articulação com outros setores } \\
\text { Relação com a gestão } \\
\text { municipal }\end{array}$ & $\begin{array}{l}\text { Articulação com outros } \\
\text { setores } \\
\text { Articulação entre } \\
\text { profissionais da equipe } \\
\text { Relação com a gestão } \\
\text { municipal } \\
\text { Recursos humanos } \\
\text { Sistemas de informação }\end{array}$ \\
\hline & Pontos fracos & - & - & - \\
\hline & $\begin{array}{c}\text { Dificuldades } \\
\text { Internas } \\
\end{array}$ & - & - & - \\
\hline & $\begin{array}{c}\text { Dificuldades } \\
\text { Externas }\end{array}$ & - & - & - \\
\hline \multirow{4}{*}{ Promoção da Saúde } & Pontos fortes & $\begin{array}{l}\text { Articulação com outros } \\
\text { setores } \\
\text { Articulação entre os } \\
\text { profissionais da equipe } \\
\text { Recursos humanos } \\
\text { Capacitação e suporte em } \\
\text { educação permanente } \\
\end{array}$ & $\begin{array}{c}\text { Articulação entre os } \\
\text { profissionais da equipe } \\
\text { Articulação com outros setores } \\
\text { Recursos materiais }\end{array}$ & $\begin{array}{l}\text { Articulação com outros } \\
\text { setores } \\
\text { Articulação entre } \\
\text { profissionais da equipe } \\
\text { Capacitação e suporte em } \\
\text { educação permanente }\end{array}$ \\
\hline & Pontos fracos & - & - & $\begin{array}{c}\text { Sistemas de informação } \\
\text { Recursos materiais }\end{array}$ \\
\hline & $\begin{array}{c}\text { Dificuldades } \\
\text { Internas } \\
\end{array}$ & - & - & Espaço físico \\
\hline & $\begin{array}{l}\text { Dificuldades } \\
\text { Externas }\end{array}$ & - & $\begin{array}{c}\text { Adesão da população idosa nas } \\
\text { ações de atividade física } \\
\text { Permanência dos fumantes } \\
\text { no Programa de Combate ao } \\
\text { Tabagismo }\end{array}$ & $\begin{array}{c}\text { Adesão dos idosos } \\
\text { Recursos financeiros da } \\
\text { população }\end{array}$ \\
\hline \multirow{4}{*}{$\begin{array}{c}\text { Vigilância da Situação } \\
\text { em Saúde }\end{array}$} & Pontos fortes & $\begin{array}{l}\text { Capacitação e suporte em } \\
\text { educação permanente } \\
\text { Articulação com outros } \\
\text { setores } \\
\text { Sistemas de informação }\end{array}$ & $\begin{array}{c}\text { Capacitação e suporte em } \\
\text { educação permanente } \\
\text { Sistemas de informação } \\
\text { Articulação entre os } \\
\text { profissionais da equipe } \\
\text { Articulação com outros setores }\end{array}$ & $\begin{array}{l}\text { Articulação com outros } \\
\text { setores } \\
\text { Articulação entre os } \\
\text { profissionais da equipe } \\
\text { Sistemas de informação }\end{array}$ \\
\hline & Pontos fracos & - & - & Recursos materiais \\
\hline & $\begin{array}{c}\text { Dificuldades } \\
\text { Internas } \\
\end{array}$ & - & - & - \\
\hline & $\begin{array}{l}\text { Dificuldades } \\
\text { Externas }\end{array}$ & - & - & - \\
\hline
\end{tabular}

às demandas de saúde, de forma integrada e intersetorial, considerando as peculiaridades de cada território na execução das ações ${ }^{9,10}$. Porém, o enfoque ampliado que o conceito de VS propõe, com contribuições multidisciplinares da epidemiologia, geografia, ciências sociais, planejamento urbano entre outras afins destoa sobremaneira da capacidade técnica da maioria dos municípios brasileiros. A falta de recursos financeiros, tecnológicos e principalmente de pessoal qualificado e envolvido nos serviços são nós críticos que inviabilizam grande parte da proposta original da $\mathrm{VS}^{10}$. Nos dados aqui apresentados, a escassez dos diversos tipos de recursos é uma constante relatada em todas as áreas da VS, sempre associada com a não execução ou execução parcial das ações de vigilância.
Um ponto peculiar da VS é que, diferentemente da área da assistência, na qual geralmente ocorre compra de serviços ao setor privado, as vigilâncias desenvolvem atividades restritas ao setor público ${ }^{11}$. Por conseguinte, o impacto da descentralização neste setor é sentido de forma muito mais intensa nos municípios, que muitas vezes não conseguem o apoio ideal do estado e da federação.

Segundo Arretche ${ }^{12}$, um processo de descentralização bem-sucedido depende muito de que as estratégias elaboradas pelos governos estaduais e federal sejam atraentes e, com isso, promova a adesão dos municípios. O ProFVS-MG, que traça metas e oferece incentivos financeiros, segue essa direção. Este projeto, de caráter pioneiro e inovador, tem como principal objetivo a 
Tabela 4. Análise das ações da Vigilância em Saúde em três municípios mineiros de pequeno e médio porte, por associação e frequência de palavras, 2015

\begin{tabular}{|c|c|c|c|c|c|c|c|c|c|c|c|c|}
\hline \multirow[b]{2}{*}{ Vigilâncias } & \multicolumn{4}{|c|}{ Município de pequeno porte $\mathrm{A}$} & \multicolumn{4}{|c|}{ Município de pequeno porte $B$} & \multicolumn{4}{|c|}{ Município de médio porte } \\
\hline & $\begin{array}{l}\text { Pontos } \\
\text { Fortes }\end{array}$ & FA & $\begin{array}{l}\text { Pontos } \\
\text { Fracos }\end{array}$ & FA & $\begin{array}{l}\text { Pontos } \\
\text { Fortes }\end{array}$ & FA & $\begin{array}{l}\text { Pontos } \\
\text { Fracos }\end{array}$ & FA & $\begin{array}{l}\text { Pontos } \\
\text { Fortes }\end{array}$ & FA & $\begin{array}{l}\text { Pontos } \\
\text { Fracos }\end{array}$ & FA \\
\hline \multirow{5}{*}{$\begin{array}{l}\text { Vigilância } \\
\text { Sanitária }\end{array}$} & $\begin{array}{l}\text { Articulação } \\
\text { entre os } \\
\text { profissionais } \\
\text { da equipe }\end{array}$ & 4 & - & - & $\begin{array}{c}\text { Capacitação } \\
\text { e suporte } \\
\text { em } \\
\text { educação } \\
\text { permanente }\end{array}$ & 5 & - & - & $\begin{array}{l}\text { Recursos } \\
\text { humanos }\end{array}$ & 5 & - & - \\
\hline & $\begin{array}{l}\text { Recursos } \\
\text { humanos }\end{array}$ & 2 & - & - & $\begin{array}{c}\text { Articulação } \\
\text { entre os } \\
\text { profissionais } \\
\text { da equipe }\end{array}$ & 2 & - & - & $\begin{array}{c}\text { Articulação } \\
\text { com outros } \\
\text { setores }\end{array}$ & 3 & - & - \\
\hline & $\begin{array}{c}\text { Capacitação } \\
\text { e suporte } \\
\text { em } \\
\text { educação } \\
\text { permanente }\end{array}$ & 2 & - & - & $\begin{array}{l}\text { Articulação } \\
\text { com outros } \\
\text { setores }\end{array}$ & 2 & - & - & $\begin{array}{l}\text { Sistemas de } \\
\text { informação }\end{array}$ & 1 & - & - \\
\hline & $\begin{array}{c}\text { Articulação } \\
\text { entre outros } \\
\text { setores }\end{array}$ & 1 & - & - & $\begin{array}{l}\text { Sistemas de } \\
\text { informação }\end{array}$ & 1 & - & - & $\begin{array}{l}\text { Articulação } \\
\text { entre os } \\
\text { profissionais } \\
\text { da equipe }\end{array}$ & 1 & - & - \\
\hline & & & & & $\begin{array}{l}\text { Recursos } \\
\text { humanos }\end{array}$ & 1 & - & - & & & & \\
\hline \multirow{5}{*}{$\begin{array}{c}\text { Vigilância } \\
\text { Epidemiológica }\end{array}$} & $\begin{array}{l}\text { Articulação } \\
\text { entre os } \\
\text { profissionais } \\
\text { da equipe }\end{array}$ & 2 & $\begin{array}{l}\text { Articulação } \\
\text { entre os } \\
\text { profissionais } \\
\text { da equipe }\end{array}$ & 1 & $\begin{array}{l}\text { Articulação } \\
\text { entre os } \\
\text { profissionais } \\
\text { da equipe }\end{array}$ & 6 & - & - & $\begin{array}{l}\text { Articulação } \\
\text { entre os } \\
\text { profissionais } \\
\text { da equipe }\end{array}$ & 7 & $\begin{array}{c}\text { Capacitação } \\
\text { e suporte } \\
\text { em } \\
\text { educação } \\
\text { permanente }\end{array}$ & 1 \\
\hline & $\begin{array}{l}\text { Sistemas de } \\
\text { informação }\end{array}$ & 2 & $\begin{array}{l}\text { Recursos } \\
\text { Humanos }\end{array}$ & 1 & $\begin{array}{l}\text { Sistemas de } \\
\text { informação }\end{array}$ & 5 & - & - & $\begin{array}{c}\text { Articulação } \\
\text { com outros } \\
\text { setores }\end{array}$ & 6 & - & - \\
\hline & $\begin{array}{c}\text { Capacitação } \\
\text { e suporte } \\
\text { em } \\
\text { educação } \\
\text { permanente }\end{array}$ & 1 & - & - & $\begin{array}{l}\text { Articulação } \\
\text { com outros } \\
\text { setores }\end{array}$ & 3 & - & - & $\begin{array}{l}\text { Sistemas de } \\
\text { informação }\end{array}$ & 5 & - & - \\
\hline & $\begin{array}{l}\text { Recursos } \\
\text { humanos }\end{array}$ & 1 & - & - & $\begin{array}{l}\text { Capacitação } \\
\text { e suporte } \\
\text { em } \\
\text { educação } \\
\text { permanente }\end{array}$ & 2 & - & - & $\begin{array}{l}\text { Recursos } \\
\text { materiais }\end{array}$ & 4 & - & - \\
\hline & & & & & $\begin{array}{l}\text { Recursos } \\
\text { humanos }\end{array}$ & 1 & - & - & $\begin{array}{l}\text { Recursos } \\
\text { humanos }\end{array}$ & 1 & - & - \\
\hline
\end{tabular}

FA: Frequência absoluta 
Tabela 4. Continuação...

\begin{tabular}{|c|c|c|c|c|c|c|c|c|c|c|c|c|}
\hline \multirow[b]{2}{*}{ Vigilâncias } & \multicolumn{4}{|c|}{ Município de pequeno porte $\mathrm{A}$} & \multicolumn{4}{|c|}{ Município de pequeno porte $B$} & \multicolumn{4}{|c|}{ Município de médio porte } \\
\hline & $\begin{array}{l}\text { Pontos } \\
\text { Fortes }\end{array}$ & FA & $\begin{array}{l}\text { Pontos } \\
\text { Fracos }\end{array}$ & FA & $\begin{array}{l}\text { Pontos } \\
\text { Fortes }\end{array}$ & FA & $\begin{array}{l}\text { Pontos } \\
\text { Fracos }\end{array}$ & FA & $\begin{array}{l}\text { Pontos } \\
\text { Fortes }\end{array}$ & FA & $\begin{array}{l}\text { Pontos } \\
\text { Fracos }\end{array}$ & FA \\
\hline \multirow{6}{*}{$\begin{array}{l}\text { Vigilância } \\
\text { Ambiental }\end{array}$} & $\begin{array}{c}\text { Capacitação } \\
\text { e suporte } \\
\text { em } \\
\text { educação } \\
\text { permanente }\end{array}$ & 3 & - & - & $\begin{array}{c}\text { Capacitação } \\
\text { e suporte } \\
\text { em } \\
\text { educação } \\
\text { permanente }\end{array}$ & 4 & $\begin{array}{c}\text { Articulação } \\
\text { com outros } \\
\text { setores }\end{array}$ & 1 & $\begin{array}{l}\text { Articulação } \\
\text { com outros } \\
\text { setores }\end{array}$ & 5 & - & - \\
\hline & $\begin{array}{l}\text { Articulação } \\
\text { com outros } \\
\text { setores }\end{array}$ & 1 & - & - & $\begin{array}{l}\text { Recursos } \\
\text { humanos }\end{array}$ & 2 & - & - & $\begin{array}{l}\text { Recursos } \\
\text { humanos }\end{array}$ & 4 & - & - \\
\hline & $\begin{array}{l}\text { Recursos } \\
\text { materiais }\end{array}$ & 1 & - & - & $\begin{array}{l}\text { Recursos } \\
\text { materiais }\end{array}$ & 2 & - & - & $\begin{array}{l}\text { Articulação } \\
\text { entre os } \\
\text { profissionais } \\
\text { da equipe }\end{array}$ & 4 & - & - \\
\hline & $\begin{array}{l}\text { Relação com } \\
\text { a gestão } \\
\text { municipal } \\
\end{array}$ & 1 & - & - & $\begin{array}{l}\text { Relação com } \\
\text { a gestão } \\
\text { municipal }\end{array}$ & 1 & - & - & $\begin{array}{l}\text { Recursos } \\
\text { materiais }\end{array}$ & 1 & - & - \\
\hline & $\begin{array}{l}\text { Sistemas de } \\
\text { informação }\end{array}$ & 1 & - & - & $\begin{array}{l}\text { Sistemas de } \\
\text { informação }\end{array}$ & 1 & - & - & & & - & - \\
\hline & & & & & $\begin{array}{l}\text { Articulação } \\
\text { entre os } \\
\text { profissionais } \\
\text { da equipe } \\
\end{array}$ & 1 & - & - & & & & \\
\hline \multirow{5}{*}{$\begin{array}{l}\text { Vigilância } \\
\text { à Saúde do } \\
\text { Trabalhador }\end{array}$} & $\begin{array}{l}\text { Articulação } \\
\text { entre os } \\
\text { profissionais } \\
\text { da equipe }\end{array}$ & 2 & - & - & $\begin{array}{c}\text { Capacitação } \\
\text { e suporte } \\
\text { em } \\
\text { educação } \\
\text { permanente }\end{array}$ & 2 & - & - & $\begin{array}{c}\text { Articulação } \\
\text { entre os } \\
\text { profissionais } \\
\text { da equipe }\end{array}$ & 4 & - & - \\
\hline & $\begin{array}{c}\text { Capacitação } \\
\text { e suporte } \\
\text { em } \\
\text { educação } \\
\text { permanente }\end{array}$ & 1 & - & - & $\begin{array}{l}\text { Articulação } \\
\text { entre os } \\
\text { profissionais } \\
\text { da equipe }\end{array}$ & 2 & - & - & $\begin{array}{l}\text { Recursos } \\
\text { humanos }\end{array}$ & 3 & - & - \\
\hline & $\begin{array}{c}\text { Articulação } \\
\text { com outros } \\
\text { setores }\end{array}$ & 1 & - & - & $\begin{array}{c}\text { Articulação } \\
\text { com outros } \\
\text { setores }\end{array}$ & 1 & - & - & $\begin{array}{c}\text { Articulação } \\
\text { com outros } \\
\text { setores }\end{array}$ & 2 & - & - \\
\hline & & & & & $\begin{array}{l}\text { Relação com } \\
\text { a gestão } \\
\text { municipal }\end{array}$ & 1 & - & - & $\begin{array}{l}\text { Sistemas de } \\
\text { informação }\end{array}$ & 2 & - & - \\
\hline & & & & & & & & & $\begin{array}{c}\text { Relação com } \\
\text { a gestão } \\
\text { municipal }\end{array}$ & 1 & - & - \\
\hline
\end{tabular}

FA: Frequência absoluta 
Tabela 4. Continuação...

\begin{tabular}{|c|c|c|c|c|c|c|c|c|c|c|c|c|}
\hline \multirow[b]{2}{*}{ Vigilâncias } & \multicolumn{4}{|c|}{ Município de pequeno porte $\mathrm{A}$} & \multicolumn{4}{|c|}{ Município de pequeno porte B } & \multicolumn{4}{|c|}{ Município de médio porte } \\
\hline & $\begin{array}{l}\text { Pontos } \\
\text { Fortes }\end{array}$ & FA & $\begin{array}{l}\text { Pontos } \\
\text { Fracos }\end{array}$ & FA & $\begin{array}{l}\text { Pontos } \\
\text { Fortes }\end{array}$ & FA & $\begin{array}{l}\text { Pontos } \\
\text { Fracos }\end{array}$ & FA & $\begin{array}{l}\text { Pontos } \\
\text { Fortes }\end{array}$ & FA & $\begin{array}{l}\text { Pontos } \\
\text { Fracos }\end{array}$ & FA \\
\hline \multirow{5}{*}{$\begin{array}{l}\text { Promoção da } \\
\text { Saúde }\end{array}$} & $\begin{array}{l}\text { Recursos } \\
\text { humanos }\end{array}$ & 2 & - & - & $\begin{array}{l}\text { Articulação } \\
\text { com outros } \\
\text { setores }\end{array}$ & 5 & - & - & $\begin{array}{l}\text { Articulação } \\
\text { entre os } \\
\text { profissionais } \\
\text { da equipe }\end{array}$ & 4 & $\begin{array}{l}\text { Recursos } \\
\text { materiais }\end{array}$ & 1 \\
\hline & $\begin{array}{l}\text { Articulação } \\
\text { com outros } \\
\text { setores }\end{array}$ & 2 & - & - & $\begin{array}{l}\text { Articulação } \\
\text { entre os } \\
\text { profissionais } \\
\text { da equipe }\end{array}$ & 3 & - & - & $\begin{array}{l}\text { Articulação } \\
\text { com outros } \\
\text { setores }\end{array}$ & 4 & $\begin{array}{l}\text { Sistemas de } \\
\text { informação }\end{array}$ & 1 \\
\hline & $\begin{array}{c}\text { Articulação } \\
\text { entre os } \\
\text { profissionais } \\
\text { da equipe }\end{array}$ & 2 & - & - & $\begin{array}{l}\text { Relação com } \\
\text { a gestão } \\
\text { municipal }\end{array}$ & 1 & - & - & $\begin{array}{l}\text { Sistemas de } \\
\text { informação }\end{array}$ & 1 & - & - \\
\hline & & & - & - & $\begin{array}{l}\text { Recursos } \\
\text { materiais }\end{array}$ & 1 & - & - & $\begin{array}{l}\text { Recursos } \\
\text { materiais }\end{array}$ & 1 & - & - \\
\hline & & & & & & & & & $\begin{array}{l}\text { Capacitação } \\
\text { e suporte } \\
\text { em } \\
\text { educação } \\
\text { permanente }\end{array}$ & 1 & - & - \\
\hline \multirow{4}{*}{$\begin{array}{l}\text { Vigilância da } \\
\text { Situação em } \\
\text { Saúde }\end{array}$} & $\begin{array}{c}\text { Capacitação } \\
\text { e suporte } \\
\text { em } \\
\text { educação } \\
\text { permanente } \\
\end{array}$ & 4 & - & - & $\begin{array}{l}\text { Capacitação } \\
\text { e suporte } \\
\text { em } \\
\text { educação } \\
\text { permanente }\end{array}$ & 5 & - & - & $\begin{array}{l}\text { Articulação } \\
\text { com outros } \\
\text { setores }\end{array}$ & 6 & $\begin{array}{l}\text { Recursos } \\
\text { materiais }\end{array}$ & 6 \\
\hline & $\begin{array}{c}\text { Articulação } \\
\text { entre outros } \\
\text { setores }\end{array}$ & 1 & - & - & $\begin{array}{l}\text { Sistemas de } \\
\text { informação }\end{array}$ & 4 & - & - & $\begin{array}{l}\text { Articulação } \\
\text { entre os } \\
\text { profissionais } \\
\text { da equipe } \\
\end{array}$ & 6 & - & - \\
\hline & $\begin{array}{l}\text { Sistemas de } \\
\text { informação }\end{array}$ & 1 & - & - & $\begin{array}{l}\text { Articulação } \\
\text { entre os } \\
\text { profissionais } \\
\text { da equipe } \\
\end{array}$ & 1 & - & - & $\begin{array}{l}\text { Sistemas de } \\
\text { informação }\end{array}$ & 6 & - & - \\
\hline & & & & & $\begin{array}{c}\text { Articulação } \\
\text { com outros } \\
\text { setores }\end{array}$ & 1 & - & - & & & & \\
\hline
\end{tabular}

FA: Frequência absoluta

consolidação de boas práticas de VS, de forma sistematizada e progressiva, levando os municípios a se organizarem e melhorarem seus sistemas de vigilância já existentes, ou a implantarem aqueles ainda inexistentes, provocando desdobramentos inclusive na rede assistencial. Este estudo não teve como objeto a avaliação do ProFVS-MG, porém foi percebido nas entrevistas que o caráter sistematizador e norteador do projeto tem contribuído sobremaneira nas condutas da VS nos municípios pesquisados.

A VIGEP nos municípios ganhou força na década de 1990 quando foi normatizada e regulamentada a sua autonomia técnico-gerencial, inclusive com regulamentação do repasse financeiro do governo federal para estados e municípios ${ }^{13,14}$. No entanto, até os dias atuais, na maioria das vezes, os sistemas de vigilância epidemiológica municipais são restritos à coleta e transmissão de dados, a maioria deles oriundos de notificações de unidades de saúde assistenciais (busca passiva). Neste estudo, a VIGEP, como era esperado, possuía a melhor estrutura. Apesar disso, como relatado por alguns entrevistados, a VIGEP talvez seja a que necessite de menor aporte estrutural. As ações de vigilância epidemiológica nos municípios pesquisados são bem executadas, muito mais pela proatividade dos profissionais e articulação com outros setores do que propriamente pela estrutura física.

A incorporação da VIGIAM na saúde pública brasileira é recente, ganhando força somente no final da década de 1990. Em decorrência de suas atribuições, a VIGIAM possui necessariamente um caráter integrador inter e intrassetorial, algo difícil de ser concretizado na prática dos serviços ${ }^{15}$. 
Esta necessidade de integração, de caráter eminentemente multidisciplinar, vai à contramão da realidade dos municípios brasileiros, que raramente possuem número suficiente de servidores e com formações específicas necessárias para as boas práticas da VIGIAM. Neste estudo, porém, foi relatado com frequência que um dos pontos fortes desta vigilância era a capacitação e suporte em educação permanente, apesar dos relatos de desconhecimento das ações da VIGIAM e preenchimento incorreto de fichas de notificação. Na prática, a VIGIAM talvez seja a vigilância que mais necessite de estrutura, seja ela laboratorial, equipamentos de campo, pessoal entre outros. Os serviços de VIGIAM prestados nos municípios pesquisados estão muito aquém daqueles preconizados para a VIGIAM no Brasil (Vigilância da qualidade da água para consumo humano - VIGIAGUA; Vigilância em saúde de populações expostas a poluentes atmosféricos - VIGIAR; Vigilância em saúde de populações expostas a contaminantes químicos VIGIPEQ; Vigilância em saúde ambiental relacionada aos riscos decorrentes de desastres - VIGIDESASTRES; e Vigilância em saúde ambiental relacionada aos fatores físicos - VIGIFIS ${ }^{16}$. Considerando que a grande maioria dos municípios mineiros também é de pequeno ou médio porte, as atribuições da VIGIAM são provavelmente as mais difíceis de serem realizadas no âmbito da VS.

Dentre as vigilâncias, a que provavelmente sofre maiores influências em relação ao porte do município é a VISA. Piovesan et al. ${ }^{17}$ citam vários fatores que reduzem a efetividade da VISA nos munícipios, porém, provavelmente, os mais influentes sejam a insuficiência de recursos humanos, interferência político-partidária, baixa qualificação técnica dos profissionais e falta de apoio político. Neste estudo, de fato, todos estes fatores foram relatados, além do aumento de demanda, que é um problema recorrente em municípios em crescimento. Nos municípios pesquisados, o nó crítico mais evidente é a equipe reduzida, o que impede que ações de busca ativa, algo imperativo em qualquer ação de VS, sejam realizadas.

A atuação proativa da VISA frequentemente interfere em relações pessoais, políticas e gera conflito de interesses entre membros da gestão, donos de estabelecimentos entre outros. Estas situações se mostram mais evidentes em municípios de pequeno porte, porém, com certeza, ocorre em todos aqueles em que as ações de vigilância sanitária são executadas. Piovesan et al. ${ }^{17}$ relataram que, apesar de $75 \%$ dos municípios pesquisados da Paraíba disporem de termos administrativos para notificação ou aplicação de sanções, raramente os utilizavam, demonstrando de certa forma as pressões sofridas pela VISA no âmbito municipal. Em nosso estudo, porém, essas relações não foram abertamente declaradas.

O setor de saúde passou a intervir nos espaços de trabalho, legalmente instituídos, a partir da Constituição Federal de
1988 e da criação do SUS. A VISAT surgiu com o intuito de promover e proteger a Saúde do Trabalhador (ST) evitando situações e condições geradoras de sofrimento, de doenças profissionais e de acidentes de trabalho ${ }^{18}$. Porém, na prática, a complexidade dos ambientes e processos de trabalho existentes, a falta de profissionais graduados e capacitados em ST da maioria das equipes dos Centros de Referência em Saúde do Trabalhador (CERESTs) dificultam a efetividade desta vigilância. Toma-se como agravante que os CERESTs são responsáveis por um grande número de municípios, e que os municípios, por si só, não possuem autonomia suficiente para a realização de ações importantes como o reconhecimento de riscos e o perfil epidemiológico e morbimortalidade dos trabalhadores. Em um estudo realizado em São Paulo, ficou demonstrado que a estrutura da VISAT é compartilhada com outros setores e com recursos materiais e humanos escassos, tornando as ações desta vigilância pouco efetiva na prática ${ }^{18}$. O compartilhamento da estrutura na VISAT também foi demonstrado neste estudo. A falta de autonomia, sem dúvida, interfere na agilidade das ações, bem como no planejamento de estratégias voltadas à saúde do trabalhador.

A aprovação da Política Nacional de Promoção da Saúde em 2006 ratificou a institucionalização da promoção da saúde no SUS, que permeia a saúde pública brasileira e mundial há décadas, desde que a importância dos determinantes sociais foi reconhecida na condução das ações de saúde ${ }^{19}$. No entanto, raramente se possui uma estrutura de promoção da saúde bem definida no SUS, um paradoxo levando em conta a magnitude das doenças crônicas no cenário epidemiológico atual. Ações desarticuladas geralmente são executadas pela atenção básica ou secretaria de esportes, porém sem uma coordenação específica. Como observado na VIGIAM e VISAT, a estrutura da Promoção da saúde nos municípios pesquisados reflete a sua recente implantação no SUS, a qual não possui estrutura física, transporte e pessoal exclusivo para o desenvolvimento das ações. No entanto, como relatado pelos participantes da pesquisa, as adaptações das atividades em áreas públicas, bem como a articulação com outros setores minimizam este déficit da estrutura. Neste sentido, fica evidente a importância da proatividade profissional no impacto dos serviços prestados à comunidade.

A avaliação de serviços de saúde constitui-se em um dos maiores problemas para a epidemiologia, devido principalmente à subjetividade implícita no processo avaliativo. Uma das abordagens mais utilizadas para a avaliação é a proposta por Donabedian ${ }^{20,21}$, em que três componentes são preconizados: estrutura, processos e resultados. Nesta proposta, a estrutura corresponde àquilo que é relativamente estável no sistema e que propicia a prestação dos serviços, incluindo os recursos financeiros, humanos, equipamentos, formas de organização, 
funcionamento e ambiente físico. A partir desta estrutura, é possível realizar os processos e, por fim, oferecer os resultados esperados. Starfield ${ }^{22}$ classifica a estrutura como a capacidade do sistema, e destaca, como fator imperativo na qualidade da estrutura, a análise de pessoal, incluindo as relações interpessoais e a qualificação profissional. O processo refere-se ao conjunto de atividades e procedimentos empregados no manejo dos recursos, e os resultados às mudanças verificadas, com benefícios diretos ou indiretos no estado de saúde da população, ocorrência de mudanças comportamentais, produção de conhecimentos, atitudes e práticas ou a satisfação dos usuários dos serviços. No entanto, segundo Vuori ${ }^{23}$, um dos pontos mais frágeis da proposta de Donabedian refere-se à ideia de que uma boa estrutura leva a um bom processo e, por conseguinte, a bons resultados. De fato, condições favoráveis de estrutura são necessárias em muitos processos de VS, porém, na maioria das vezes a excelência profissional é imperativa na eficiência das ações, sendo estas realizadas em condições adversas ou não. Neste estudo, em vários relatos dos entrevistados, foi verificado que a atuação da equipe foi essencial na execução das ações, mesmo com estrutura precária.

O campo de avaliação de serviços e programas historicamente foi baseado em pressupostos positivistas, se utilizando preferencialmente de dados quantitativos ${ }^{24}$. Porém, ao longo das últimas décadas, a análise qualitativa ganhou destaque em estudos de avaliaçãa ${ }^{25-27}$. Estes estudos propõem-se não somente à mensuração de dados, de caráter objetivo, mas também à análise das experiências dos atores sociais, sejam eles usuários, técnicos, gestores ou políticos, aprofundando a compreensão do objeto de estudo ${ }^{28,29}$. Sem o intuito de se considerar uma metodologia (quali ou quanti) superior à outra, o estudo aqui apresentado pretende contribuir com a tendência de complementaridade entre elas, na busca da compreensão mais completa do objeto de estudo ${ }^{30}$.

\section{REFERÊNCIAS}

1. Levcovitz E, Lima LD, Machado CV. Política de saúde nos anos 90: relações intergovernamentais e o papel das Normas Operacionais Básicas. Cien Saude Colet. 2001;6(2):269-91. http://dx.doi.org/10.1590/S1413-81232001000200002.

2. Spedo SM, Tanaka OY, Pinto NRS. O desafio da descentralização do Sistema Unico de Saúde em município de grande porte: o caso de São Paulo, Brasil. Cad Saude Publica. 2009;25(8):1781-90. PMid:19649419. http://dx.doi. org/10.1590/S0102-311X2009000800014.

3. Instituto Brasileiro de Geografia e Estatística. Estimativa populacional 2015 com data de referência em $1^{\circ}$ de julho de 2015 [Internet]. Rio de Janeiro; 2015 [citado em 2015 nov 20]. Disponível em: ftp://ftp.ibge.gov.br/ Estimativas_de_Populacao/Estimativas_2015/estimativa_dou_2015_20150915. pdf

4. Minas Gerais. Resolução SES n 3.152, de 14 de fevereiro de 2012. Aprova o edital de convocação para adesão dos municípios ao Projeto de Fortalecimento da Vigilância em Saúde no Estado de Minas Gerais. Diário Oficial do Estado de Minas Gerais, Belo Horizonte, 29 de fevereiro de 2012.

5. Instituto Brasileiro de Geografia e Estatística. Estimativas da população dos municípios brasileiros com data de referencia em $1^{\circ}$ de julho de 2014 [Internet]. Rio de Janeiro; 2015 [citado em 2015 nov 20]. Disponível em: http:// www.ibge.gov.br/home/presidencia/noticias/pdf/analise_estimativas_2014. pdf

6. Brasil. Ministério da Saúde. Diagnóstico Local da Vigilância em Saúde 2014 [Internet]. Brasília; 2014 [citado em 2015 nov 20]. Disponível em: http://formsus.datasus.gov.br/site/formulario.php?id_aplicacao=14834

7. Laguardia FC, Quintino ND, Gusmão RB, Moraes CAL, Oliveira PBB. Instrutivo para execução e avaliação das ações de vigilância em saúde: projeto fortalecimento da vigilância em saúde em Minas Gerais. Belo Horizonte: Secretaria Estadual de Saúde de Minas Gerais; 2014. 400 p.

8. Bardin L. Análise de Conteúdo. Lisboa: Edições 70; 2011.

9. Brasil. Ministério da Saúde. Secretaria de Vigilância em Saúde. Vigilância em saúde no SUS: fortalecendo a capacidade de resposta aos velhos e novos desafios. Brasília; 2006
10. Oliveira CM, Cruz MM. Sistema de Vigilância em Saúde no Brasil: avanços e desafios. Saúde Em Debate. 2015;39(104):255-67. http://dx.doi. org/10.1590/0103-110420151040385.

11. Cohen MM, Moura MLO, Tomazelli JG. Decentralization of Health Surveillance actions in cities with local health managment in the State of Rio de Janeiro. Rev Bras Epidemiol. 2004;7(3):290-301. http://dx.doi. org/10.1590/S1415-790X2004000300007.

12. Arretche MT. Políticas sociais no Brasil: descentralização em um Estado federativo. Rev Bras Cienc Sociais. 1999;14(40):111-41. http://dx.doi. org/10.1590/S0102-69091999000200009.

13. Brasil. Ministério da Saúde. Portaria n 2.203, de 05 de novembro de 1996 Aprova a Norma Operacional Básica 1/96. Diário Oficial da União, Brasília, 1996; 05 nov.

14. Brasil. Ministério da Saúde. Portaria no 1.399, de 15 de dezembro de 1999. Regulamenta a NOB SUS 01/96 no que se refere às competências da União, estados, municípios e Distrito Federal, na área de epidemiologia e controle de doenças e define a sistemática de financiamento. Diário Oficial da União, Brasília, 1999; 15 dez.

15. Barcellos C, Quitério LAD. Vigilância ambiental em saúde e sua implantação no Sistema Único de Saúde. Rev Saude Publica. 2006;40(1):170-7. PMid:16410998. http://dx.doi.org/10.1590/S0034-89102006000100025.

16. Brasil. Ministério da Saúde. Instrução Normativa N.1 de 7 de março de 2005. Regulamenta a Portaria GM/MS nº. 1.172/2004/GM, no que se refere as competências da União, estados, municípios e do Distrito Federal na área de vigilância em saúde ambiental. Diário Oficial da União, Brasília, 2005; 07 mar.

17. Piovesan MF, Padrão MVV, Dumont MU, Gondim GM, Flores O, Pedrosa JI, et al. Vigilância sanitária: uma proposta de análise dos contextos locais Rev Bras Epidemiol. 2005;8(1):83-95. http://dx.doi.org/10.1590/S1415790X2005000100010

18. Vilela RAG. Desafios da vigilância e da prevenção dos acidentes do trabalho. São Paulo: LTR; 2003. 
19. Malta DC, Castro AM, de Gosch CS, Cruz DKA, Bressan A, Nogueira JD, et al. A Política Nacional de Promoção da Saúde e a agenda da atividade física no contexto do SUS. Epidemiol Serv Saude. 2009;18(1):79-86.

20. Donabedian A. The definition of quality and approaches to its assessment. Ann Arbor: Health Administration Press; 1980. (Avedis Donabedian Explorations in Quality Assessment and Monitoring, vol. 1).

21. Donabedian A. The quality of care: how can it be assessed? JAMA. 1988;260(12):1743-8. PMid:3045356. http://dx.doi.org/10.1001/ jama.1988.03410120089033.

22. Starfield B. Atenção primária: equilíbrio entre necessidades de saúde, serviços e tecnologia. 2. ed. Brasília: Unesco; 2004.

23. Vuori HA. Qualidade em saúde. Divulg Saúde Debate. 1991;3:17-25.

24. Lobo T. Avaliação de processos e impactos em programas sociais: algumas questões para reflexão. In: Rico EM, editor. Avaliação de Políticas Sociais. São Paulo: Cortez; 1998. p. 75-84.

25. Bosi MLM, Affonso KC. Cidadania, participação popular e saúde: com a palavra, os usuários da rede pública de serviços. Cad Saude Publica. 1998;14(2):355-65. PMid:9658221. http://dx.doi.org/10.1590/S0102311X1998000200020.
26. Minayo MCS, Souza ER, Assis SG, Cruz No O, Deslandes SF, Silva CMPF. Avaliação dos Centros de Orientação e Apoio Sorológico/CTA/Coas da Região Nordeste do Brasil. Cad Saude Publica. 1999;15(2):355-67. PMid:10409788. http://dx.doi.org/10.1590/S0102-311X1999000200020.

27. Nuto SS, Nations MK. Avaliação qualitativa dos serviços como processo de construção de cidadania. Ação Coletiva. 1999;2(3):25-9.

28. Bosi MLM, Pontes RJS, Vasconcelos S. Dimensões da qualidade na avaliação em saúde: concepções de gestores. Rev Saude Publica. 2010;44(2):318-24. PMid:20339631. http://dx.doi.org/10.1590/S0034-89102010000200012.

29. Uchimura KY, Bosi MLM. Qualidade e subjetividade na avaliação de programas e serviços em saúde. Cad Saude Publica. 2002;18(6):1561-9. PMid:12488882. http://dx.doi.org/10.1590/S0102-311X2002000600009.

30. Minayo MCS, Minayo-Gómez C. Difíceis e possíveis relações entre métodos quantitativos e qualitativos nos estudos de problemas de saúde. In: Goldenberg P, Marsiglia RMG, Gomes MHA, editores. O Clássico e o Novo: tendências, objetos e abordagens em ciências sociais e saúde. Rio de Janeiro: Fiocruz; 2003. p. 117-142.

Recebido em: Nov. 24, 2016 Aprovado em: Mar. 11, 2017 